\title{
DEVELOPMENT OF SUSTAINABLE FINANCE THROUGH THE PRISM OF VALUE PARADIGM
}

\author{
Ghenadie CIOBANU ${ }^{*}$, Dan BOBOC ${ }^{b}$, Cristina DIMA ${ }^{c}$, Evelina BALU ${ }^{d}$, \\ Carol Cristina GOMBOS \\ ${ }^{a}$ National Scientifc Research Institute for Labour and Social Protection, Bucharest, Romania \\ $b, c, d, e$ Bucharest University of Economic Studies, Romania
}

DOI: $10.24818 / \mathrm{IMC} / 2020 / 01.18$

\begin{abstract}
Given the strategic priorities of sustainable development, the objectives of development strategies at national and European level, the field of sustainable finance has also developed. Therefore, in this article we aim to come up with the value paradigm.

In this paper we set out to review an analysis regarding transdisciplinary studies related to interdisciplinarity, thermodynamic laws applied in economics.

We believe that both the field of sustainable economy and especially sustainable finance can benefit from the value paradigm proposed by the author and we can build new models of sustainable development and sustainable finance (public, private, international) using value theory entropy.
\end{abstract}

KEYWORDS : sustainable finance , Financial policy, sustainable economy.

\section{INTRODUCTION}

In this article we aim to review the issue of sustainable finance development, and the proposal to apply a new value paradigm to sustainable finance. The new Romania's Sustainable Development Strategy 2030 stipulates that global finance Global finances still need corrective action: Availability of loans granted under easy conditions, a short-term vision and excessive risk-taking in financial markets around the world has encouraged speculative behavior, contributing to the growth of speculative bubble growth and the creation of significant imbalances. Europe is committed to finding global solutions to establish an efficient and sustainable financial system. According to (Schoenmaker \& Schramade, 2019): Europe is committed to finding global solutions to establish an efficient and sustainable financial system. According to (Schoenmaker \& Schramade, 2019): "Sustainable development must ensure and support both current and future generations with the necessary resources, such as food, water, energy and health care, without accentuating the processes of the Earth's financial system. Sustainable is the way in which financial mechanisms (investments and loans) are correlated with economic, social and environmental issues." The authors are of the opinion that: "sustainable financing analyses to what extent the financing activity with the help of the differentiated palette of financial instruments (investments, loans, etc.) correlates with the economic, social and environmental problems". The authors argue that: "In funding activities, they can influence strategic decisions about trade-offs between sustainable development goals. Investors can influence the corporations they invest in. Long-term investment can guide corporations toward sustainable business." Therefore, "financing has a high price risk for assessment purposes and can help address uncertainty about environmental issues, such as the impact of carbon emissions on climate change. The transition to a paradigm and a way of sustainable financing has gone through different stages. In recent decades, the emphasis has gradually shifted to short-term profit to long-

\footnotetext{
* Corresponding author. E-mail address: gciobanu01@gmail.com
} 
term value creation." (Schoenmaker \& Schramade, 2019). Therefore, the ideology and the respective plans as action plans for the well-being of people, the planet and prosperity, is aimed at consolidating universal peace. Eradicating poverty in all its forms is one of the major challenges and a requirement for sustainable development (United Nations, 2015).

The respective agenda as an action plan for the well-being of the people, the planet and prosperity, aims at consolidating universal peace. Eradicating poverty in all its forms is the biggest challenge and one of the requirements for sustainable development (United Nations, 2015).

According World Bank Group (2017), markets have driven the development of financial products, information and sustainable technological innovations. Financial institutions (FIs) have begun to transform to adapt their business models, skills and incentives to incorporate sustainability into their core strategies. Market transformations need to be accelerated to meet global sustainability requirements. This activity requires the efficient coordination of national and international initiatives, in order to promote the processes of transition to sustainable financing, the production of additional regulations in order to increase the pace of change.

National leading initiatives for sustainable finance (World Bank Group, 2017) and the multiplicity of market failures that constitute barriers to sustainable financing require governments to initiate, support and accelerate its development through the use of fiscal resources and public policy measures. A systematic approach is needed to select government interventions; activity that can be achieved by developing national sustainable financing roadmaps, with broad support in all government and private sector activities. Public finance measures, through the government's response with fiscal implications, which can be classified into four categories, depending on the area of involvement and instruments. It is also important to classify government interventions in support of sustainable financing that involve financial expenditures or abandoned revenues. Therefore, a complete catalog of potential interventions is not needed, but a classification that can guide the development of specific national approaches. The horizontal dimension refers to those actions that are or are not, taken directly in support of the financial system, or whether they seek to support the real sector of the economy or other parts of government to facilitate their engagement with the financial sector. The vertical dimension classifies them according to the mechanism used: direct financing, which includes risk-sharing mechanisms; or activities in support of the "favorable environment" that would facilitate the functioning of a sustainable financial system.

Financial policy and regulation. According World Bank Group (2017), public authorities including governments, central banks, regulators, supervisors and other bodies - take legislative, policy, regulatory and supervisory measures to achieve a number of objectives linking sustainability and the system. such as: Improving market practice, including efforts to integrate environmental factors into financial decision-making and correct market failures (such as invaluable environmental externalities).

Let's start with the definition of Sustainable Financing, World Bank Group (2017), which can be understood as a broad concept defined by the use given to tight and allocated resources. Although the definition of concepts such as ESG and impact investment is based on the approaches used to select investments and investor objectives, the definition of sustainable financing and concepts such as climate and green financing refers to the use of financial resources. Sustainable financing is a broader and newer concept, the significance of which is still evolving.

SUSTAINABLE FINANCE SUBSET: CLIMATE FINANCING AND GREEN FINANCING Further clarifications of the meaning of sustainable financing can be obtained by defining a sustainable financing subgroup; these definitions are sometimes erroneously used interchangeably. The UN Environmental Survey has prepared a baseline note on the definition and concepts. 


\section{NEW VALUE PARADIGM TO SUSTAINABLE FINANCE}

\subsection{Financing for Sustainable}

Simultaneously with the adoption of the 2015 Paris Agreement on Climate Change and the UN 2030 Agenda for Sustainable Development (World Bank Group, 2017), governments around the world have chosen the path of sustainable development for the planet's development and economic development. As it increasingly confronts the unpredictable consequences of climate change, resource depletion, and other activities, urgent action is needed to adapt and implement public policies to this new reality. Therefore, the financial system is changing radically. The report argues that sustainable financing addresses two imperative issues: (1) enhancing the contribution of financing to sustainable and inclusive growth through long-term financing of development and society's needs; (2) Financial stability is needed through stabilization, environmental incorporation, social support and the impact of government factors in investment decisions. Respectively, the Report proposes eight key recommendations, some horizontal recommendations and actions to support specific sectors of the financial system. (1) The financing of sustainable development, which supports the economy and provides financing for economic activities, supports the creation and growth of jobs. Redesigning capital flows for the development of a sustainable economy. Integration of sustainable development systems in risk management. It is welcome that social and environmental objectives be included in the financial field. The decision-making process is intended to limit the financial and social impact and environmental risks. A place belongs to the promotion of transparency and the development of a long-term vision. The transparent activity of the market participants is essential for the efficient and sustainable functioning of the financial system. The issue of transparency of sustainability in the company's activity is a necessary condition to allow the participant in the financial market to evaluate the long-term value-creating companies and the way in which the management of sustainability risks is managed. Another important directive is the reorientation and redesign of capital flows towards a sustainable economy. A classification system that integrates sustainable activities to direct capital flows to sustainable economic activities must be based on the paradigm of sustainable development.

We want to highlight the main actions:

Action (1) Establish a European Union classification system for sustainable activities. It is necessary to ensure the progressive development of a taxonomy for sustainable social and ecological activities related to climate change, based on existing activities. Standards and labels for the development of sustainable financial products.

Action (2) Creation of standards and labels for green financial products. As a first step, the Commission Group of Technical Experts on Sustainable Finance will draw up a report on the European Union for Green Bonds, based on the results of a public consultation, based on current best practices.

Action (3) Stimulating investment in sustainable projects Building on ongoing efforts to strengthen consultative capacity, including the development of sustainable infrastructure, the Commission will approve additional measures to increase the efficiency and impact of instruments to support sustainable investment in the European Union and partner countries. Measures are needed to integrate sustainability considerations into financial advice.

Action (4): Sustainability must be integrated into the process of provision, financial advice. Sustainability preferences are taken into account when assessing adequacy. Respectively, we need to develop sustainability standards, which play an important role in pricing financial instruments and other relevant assets within the financial system. These indices are useful tools for investors, as they allow performance tracking and measurement, as well as asset allocation.

Action (5) Development of sustainability criteria. Delegated acts (i) which have been adopted by the reference regulation on the transparency of the methodologies used and the characteristics of the benchmarks to enable users to assess quality in terms of sustainability; and (ii) present, depending 
on the outcome of the impact assessment. It is necessary to integrate sustainability into risk management.

Sustainability in market research and credit ratings. In recent years, market research providers and rating agencies for sustainable development have stepped up their work, efforts to assess environmental performance, social development and corporate governance; as well as the ability to manage sustainability risks.

Action (6) Integrating sustainability into ratings and market research. Amendments have been made made to the "Regulation on credit rating agencies" which would require credit rating agencies to explicitly integrate sustainability factors into their assessments in a proportionate manner so that smaller actors can have further market access. Obligations of institutional investors and asset managers in terms of sustainability are also needed. Several EU legislation acts require institutional investors and asset managers to act in the best interests of their final investors / beneficiaries. This obligation is usually referred to as the "fiduciary duty".

Action (7): Clarify the obligations of institutional investors and asset managers Based on the results of the impact assessment, and legislative proposals have been made to clarify the obligations of institutional investors and asset managers with regard to sustainability considerations. Prudential requirements for banks and insurance companies are also needed Banks, insurance companies and pension funds are the main source of external financing for the European economy and are an important vector for transforming savings into investments.

Action (8): Incorporate sustainability into prudential requirements 1 . The Commission will examine the feasibility of including risks related to climate change and other environmental factors in institutions' risk management policies, as well as the feasibility of potentially calibrating capital requirements for banks as part of the Regulation. and the Capital Requirements Directive. The aim would be to take such factors into account, where justified in terms of risks, in order to ensure the coherence and effectiveness of the prudential framework and financial stability. An important role is to promote transparency and long-term vision. Communication of information and accounting rules. The communication of information on sustainability issues by businesses allows investors and stakeholders to assess the extent to which businesses create long-term value and are exposed to sustainability risks.

Action (9): Strengthen the communication of sustainability information and develop accounting standards. The Commission is also launching a review of the adequacy of EU legislation on public disclosure by companies, including the Non-Financial Disclosure Directive, to assess whether public reporting requirements for listed and unlisted companies are appropriate for the purpose. Corporate governance and the unjustified short-term vision of the capital market are important. Corporate governance can make a significant contribution to a more sustainable economy by enabling businesses to take the necessary strategic steps to develop new technologies.

Action 10: Promote sustainable corporate governance and mitigate the short-term vision of capital markets. In order to promote corporate governance that is more conducive to sustainable investment, the Commission will carry out analysis and consultation with relevant stakeholders by the second quarter of 2019 to assess the following issues: (i) the possible need to require the boards of directors of companies to draw up and publish a sustainability strategy, including a duty of care along the supply chain, as well as measurable sustainability targets, and (ii) the possible need to clarify the rules under which directors must act in the long-term interest of the company.

\subsection{Bibliographic study of interdisciplinarity issues in economics applicable in the sustainable economy and sustainable sustainable finance}

Theoretically, the authors (Ziolo et al., 2019) recently showed that funding is an engine of sustainable development. In order to achieve sustainability through financing mechanisms, it is necessary to rebuild and adapt the financial system to the mechanisms of sustainable development. Contemporary financial systems can be described with a one-dimensional emphasis on ensuring the 
economic security of transactions. Over time, the major role of risk related to non-financial factors means that environmental, social and governance factors (also called ESG - environmental, social, governance) become the main sources that threaten the stability and sustainability of financial systems. The activities of adaptation to the design and redesign of three-dimensional financial systems are based on the incorporation of ESG risk in the financial management activity of the financial institutions that make up the financial system. This is also found in other risk assessment methodologies. The overall objective of the paper is to investigate what ESG criteria are incorporated into the decision-making process of financial institutions, and to verify the level of sustainability of financial systems in certain OECD countries. The priority research hypothesis assumes that the incorporation of ESG factors in the decision-making process of financial institutions increases the activity of sustainable financial systems. To achieve the research objective, a two-stage research procedure was used. In the first stage, an unclear cognitive map (FCM) was used to determine the ESG factors that affect the sustainability of financial systems and to identify the dependencies between the ESG factors incorporated by financial institutions in the decisionmaking process. The map developed based on the opinions of the experts participating in the study were developed using the software FCMapper_bugfix_27.1.2016. In the second stage, based on the analysis of multi-criteria decisions (MCDA) using the PROMETHEE method, 23 OECD countries that respect the principles of the equator were classified according to seven groups of criteria defined for evaluating the financial system (financial depth, development, vulnerability, solidity, fragility, stability and durability), based on the bibliographic review in the field. The ranking confirmed its strong position in the Scandinavian countries to ensure best practices in sustainability in financial institutions and the economy. The value of this paper can be considered at two levels: theoretical and empirical. From a theoretical point of view, we want to note that it is the first of this type of analysis that prioritizes ESG factors in financial decisions and classifies financial systems according to sustainability criteria. The original empirical approach based on the two-stage research procedure provided the analysis of 62 factors, of which 21 represented the environmental sphere, 25 the social sphere and 16 the governance sphere, which is the main advantage of the empirical study presented in the study. The authors (Fatemi \& Fooladi, 2013) argue: "The current approach to maximizing shareholder wealth is not a valid guide to creating sustainable wealth: a focus on longterm results. The great confidence in the ability of markets to effectively discover the long-term value implications of short-term outcomes has created many unacceptable outcomes." The authors consider: "Given the future social and environmental challenges, their unacceptable practices and results cannot be sustained, a paradigm shift is needed." Respectively, they propose a sustainable value creation framework in which all social and environmental costs and benefits are explicitly taken into account.

Ryszawska (2018) argues that: "The transition to a smart, efficient low-carbon economy in conventional reception is associated with the process of multi-level transformation of the economic and socio-technological system to increase sustainability its environmental and social equity. "Given the respective transition, new financing concepts have appeared in the public debates, such as: ecological financing, sustainable financing, climate financing, carbon financing. The new approach to finance is goal-oriented, mission-oriented and value-oriented, as opposed to the traditional role of finance." Therefore, transition research develops co-evolutionary approaches that highlight the multidimensional interactions between industry, technology, markets, policies, culture and civil society. The authors present a paradigm shift in the economy, which changes the role of finance (financial agents and markets) from a dominant perspective on finance, focusing only on profits and shareholder value as an alternative to the current regime. The aim is to identify a new direction for funding that is already emerging in Europe and to confirm it through numerous initiatives taken in the international arena. 


\subsubsection{The impact of interdisciplinary on the development of a new paradigm of sustainable economic and financial development}

In our opinion, it is important to develop a theoretical support to support sustainable finance. In this context, since 1880, in S.A. Podolinsky's work, "Human Labor and Its Relation to the Distribution of Energy" (Podolinsky, 1991), he developed the concept of social energy, the role of human labor in retention, accumulation, protection against dispersal, and theft transformation of the forms of solar energy, necessary to meet people's needs. Today we know the truth, the encyclopedist, the economist, the philosopher, the physician and the mathematician S.A. Podolinsky did not receive the necessary recognition and many years ago he was practically forgotten. Based on the concept of social energy, improvements were made in the twentieth century, including Vernadsky's teachings on the relationship between solar energy and living matter, with a great scientific influence on thinking and technology. Professor Nicholas Georgescu-Roegen is considered the founder of bioeconomic theory. This theory presents production as a transformation of a constant supply of materials and energy, which must obey the law of entropy, which applies to all closed systems: entropy or the amount of inaccessible matter and energy tends to increase continuously, while the amount of matter available and energy tends to decrease continuously (Georgescu-Roegen, 1971).

Among the Romanian economists of the Romanian school, a passionate successor of the development of that school is Professor Paul Bran, who developed the theory of the value of entropy. In the author's opinion "Since value is the object of work of financial distribution we can not be indifferent to the correct nature of economic theory that specifies what is and by what mechanism is obtained and managed value in today's economy" (Bran, 2003). The author considers that the theory of value based on low entropy (TVE) recognizes as an objective foundation for all processes engaged in obtaining and managing value the most general laws of nature, the law of conservation of matter and the law of entropy (Bran, 2003).

In order to better understand what entropy is what is thermodynamics, we set out to turn to the sources of physicists Sorin Anghel and Constantin Stănescu, to see what the object is and what are the fundamental notions of classical thermodynamics. So: "Thermodynamics is a method of studying thermal phenomena, phenomena determined by the thermal motion of atoms and molecules. Thermodynamics studies the macroscopic consequences of thermal motion, as well as the correlation between thermal phenomena and other types of phenomena (mechanical, electromagnetic, chemical, etc.), which they accompany.

\section{Principles of thermodynamics}

Principle 1 of thermodynamics - The law of energy transformation and conservation (Anghel \& Stănescu, 2016). A series of experimental facts to the study of which Mayer, Jouke, Halmholz contributed, led to the conclusion that in natural processes, the total energy of systems is not created and does not disappear, being possible either the transfer of energy from one system to another or transformation energy from one form to another. Principle I of thermodynamics expresses the law of conservation and transformation of energy into natural processes and essentially indicates the quantitative equivalence between mechanical work and heat.

This principle is not sufficient to describe thermal phenomena and is complemented by the second principle, which mainly refers to the following aspects: indicates the direction of natural phenomena, sets maximum limits for periodic conversion of heat into mechanical work, states the qualitative inequality of heat and mechanical work, gives a statistical-probabilistic interpretation of the development of natural phenomena.

The second principle of thermodynamics (Anghel \& Stănescu, 2016), can also be formulated as follows: in any natural process, described by a system, the total entropy of the system and the external environment increases. In the study "The Study on University Financial Management under Knowledge Economy" (Yongfan, 2012), the wave of development of the knowledge economy creates an unprecedented situation of economic development. The trend of globalization of 
education, as well as the media, often frequently updated, have severely affected the financial management system. Together with the profound evolution of the industrialization of education and the development of the socialization of logistics management, the system and content of financial management produce more and more expenses and become more and more complex and lead to new challenges and problems of financial management. Based on the new situation of the university's financial management, experts such as Hou Shanqin pointed out the lack of decisionmaking power and the lack of financial analysis capacity, while Liu Jin proposed creative thoughts of the university's financial management.

\subsubsection{Knowledge economy. The characteristics of the knowledge economy}

According to the OECD, the definition of the knowledge economy is based on knowledge, which is established on the basis of the production, storage, attribution and use of information and knowledge, while scientific technology serves as a key.

The new financial situation based on the knowledge economy. Our country is facing a much more open and market-oriented world, with integration into the world economy. International communication and cooperation in various fields is widely infused in financial investment, trade, nationalization of enterprises and nationalization of education.

New problems and analysis in university financial management based on the knowledge economy. The market economy has closely linked the university with society, so the university needs to improve the quality of education, hardware construction and driving conditions as follows:

- the complete credit system affects the financial management of the university;

- logistic socialization affects the financial management of the university;

- there are institutional defects in the financial management system of the university;

- lack of economic-scientific decision-making.

Measures to address financial management issues include:

- diversity of university capital sources, which affect financial management.

- positive support for diversified capital raising;

- a reasonable basis for charging and methods of charging shall be made. The complete credit system increases the flexibility of students' study time, so that any extension would increase teaching costs;

- To provide logistics services that operate on the basis of market economy rules;

- check the liability scale. Risk awareness must be established in the use of bank loans and the scale and duration of the loan must be determined rationally;

- with the rise of information technology and financial information management, financial management software has become an even more important tool for accounting audit and management.

As a methodological support of this topic, we research the works "Enterprise Finance" and "Value Economics" of Professor Bran (Bran, 2003; Bran, 2004). In these works, the author argues that the financial activity of the enterprise opts for the dimension of value in the enterprise system, of all processes in which the value system is engaged, and to a certain extent of processes in the natural environment and society as a whole, with all processes and existing phenomena which, at first sight, would have nothing to do with economic activity in general, and even more so with financial activity and the enterprise which is at the microeconomic level of activity. The coordination, the management of the economic activity of the economic agents, either small and medium enterprises, or large enterprises or corporations, requires in its activity to make certain forecasts in the operative and perspective financial activity. Therefore, the managers of the enterprise are obliged to carry out the short, medium and long term design of the financial dimension of the economic employees, in a dynamic context of changes in the economic, ecological, social, political and external monetaryfinancial universe of the enterprise (Bran, 2003). 


\subsubsection{Enterprise}

The size of the enterprise: the technical-economic dimension, the managerial dimension, the social dimension, the ecological dimension and the financial dimension.

Therefore, the theory of events studies the typology of the processes to which the ensembles are subjected, of the composite objects, regardless of the field of existence, respectively of the objects composed of non-living parts or living parts. Social ensembles are composed of people (family, nation), and social ensembles are composed of people and non-living objects (enterprises, institutions).

In the managerial activity of the enterprise, a special role belongs to the problem of motivation of the economic activity, which aims to bring in the society the potential necessary to maintain the system of the whole society which is in a state far from equilibrium. Therefore this potential contained in the elementary forms of matter, substance (s), energy (e) and information (i), is subject to repeated transformations and preservations, achievable through basic processes (production, consumption, liquidation), processes that have place in the natural environment, in society and in the economy. Through the consumption process, the system (natural, social, economic) is "loaded" with economic potential. This potential is preserved in the form of services, the rule by which the substance (s), energy (e) and information (i) are combined.

Therefore, the service-defining relationship (provided by man, for example) is the energy (e) put into the service of information (i), with the help of the substance (s) of the body. Regarding the production, the respective process is meant to "take out" the potential preserved in the company structure and to preserve it as a product.

The product definition relationship is information (i) implemented in the substance (s) using the energy (e). In the case of the liquidation process, it has the role of dismantling the system in question, obtaining product or service components (or elementary components of matter) that are transferred to other systems.

The processes participating in obtaining value are the primary processes and the complex processes. Broadening the range of processes, the theories of value-labor and value-utility considered that value results only from the processes that take place in economic systems.

The reconsideration of the process category by the geographical extension allowed by the valueentropy theory, in the sense of attracting new systems in the mechanism of obtaining and managing the value, it is necessary to investigate the processes that take place in these systems.

The transformation process (Bran, 2004). The first primary process: according to the Big Bang scenario, in the second 10-43 (or Plank's time) there was a first process that allowed the transformation of the initial pure energy into elementary particles and primary forces. Conservation is the second primary process: the particles and radiation produced by the first process have entered the process of preserving these primary products in the form of stable structures of matter: substance (s), free energy (e), information (i). Transfer is the third primary process: based on observations on natural phenomena, it is hypothesized that there is a third primary process in the form of transfer. The products of the first two primary processes are moved in space and time by means of the third primary process, becoming outputs, for one system, and inputs, for another system.

Paul Bran says in Value Economics that: "The theory and law of value-entropy argues that: economic processes, social processes and more and more processes in the natural environment take place, in terms of value, within the possible economic potential to be maintained in the economy during the chain of production, consumption, liquidation processes" (Bran, 2004).

\subsubsection{Financial design of the enterprise}

The purpose of financing projects and determining the financial dimensions of enterprises is main for financial activities. The starting point for achieving its objectives is clearer in the economic, 
political, social and financial and monetary context in the care of the action now and in the perspective of the enterprise. The objectives of financial design are as follows:

- Substantiation of financial decisions on consumption - in terms of consumption processes in the enterprise, society and environment, nature design, subsequent financing, substantiation of decisions related to all types of care activities, through consumption of importance in terms of care is possible, performs training, restoration, can create clarity for the elements of the enterprise.

- Substantiation of financial decisions on the product - with regard to production processes, it is possible to design the financing by which a financing is decided regarding the transformation of a value within the enterprises in conditions of conservation in products and recognized on the consumer market.

- Substantiation of financial decisions regarding external flows - regarding the contacting of financing with external environments to the enterprise, the financing design probes and evaluates the flow of funds, possibilities to adjust the budget of the units concerned, while increasing cash flows that will please the company for mandatory and banking honors for owners, business partners and other beneficiaries.

Stoletov (2003) has shown a theoretical and methodological approach to improve the system to ensure the sustainable development of industrial enterprises in terms of information component. Proposes the study of the composition and structure of the information resources of the enterprise from the position of ensuring sustainable development; identification of key areas for ensuring the sustainable development of the enterprise on the information component; determines the principles of classifying the company's information resources in the interest of sustainable development; improving and optimizing the system to ensure the sustainable development of the enterprise in terms of the information component. The results of that research are the methodological basis for building an economically oriented enterprise information security system and for intensifying the use of the organization's information resources in its economic activities to ensure sustainable development.

The methodological bases of the information and the analytical support for the sustainable development of the enterprise consist in determining the informational needs of the management of the organization, for this it is necessary to analyze the informational field, that is, all the information resources that already exist or will be created before management decisions are made.

In the opinion of the author (Melinikov, 2011) economy is a set of indivisible (quantum) primary structures, actions, and economic relations that describe the economic interactions between the objects of economic action in space and time. The paper presents the conditions for building a quantum economy of actions, the automatic generation of quantum information, checking the correctness of economic information and building the equilibrium equations of cost release.

In the opinion of the author (Slovohotov, 2012) is presented with a systematic review of foreign and Russian papers on socio physics, a new scientific field that studies social phenomena using methods of theoretical and experimental physics. The first part briefly presents the main areas of intersection of physics with social disciplines and some of the problems of social dynamics that have become part of its interests: the influence of climate and solar activity on historical events, modeling traffic and other "living" particle systems, states discrete and spontaneous transitions to such systems. The following parts present the structure and dynamics of social interaction networks, a physical description of economics (econophysics), formal models of sociology, cultural studies, political science, linguistics and mathematical history. Academic aspects and applications of socio physical research are discussed.

Authors Zhou, Cai \& Tong (2013) although the concept of entropy has its origins in thermodynamics, the principles of maximum and minimum inter-entropy entropy have been widely applied in the financial field. Those authors reviewed the concepts and principles of entropy, as well 
as the applications in the field of finance, in particular in portfolio selection and asset pricing. In addition, they analyzed the effects of the application of entropy and comparisons with other traditional methods. Therefore, the application of entropy in finance can be considered as the extension of informational entropy and probability entropy.

\section{DISCUSSION AND CONCLUSIONS}

Limited opportunities of current systems engaged in the procurement mechanism and value management due to the limitation only to economic systems without using the systemic potential of the natural environment, and without involving the potential of processes in society. An important element for economic theories of value is the spectrum of systems engaged in obtaining value.

For the construction of the model it is necessary to take into account the power supplies with the potential necessary for economic processes. It is necessary to follow the chain of processes that will practically define the value of a product by recognizing the systems involved in obtaining value.

Due to the opening of the global financial and economic system, the effects of determinism and unpredictability - the main components of chaotic systems - participate in the development of the economy and financial markets. One consequence of maximizing the entropy of financial and economic systems is the stability of the exponential distribution of money, which leads to increased inequality. "The allocation of asymmetric resources means that the current type of markets operates in unfair conditions (in this case a small group of economic agents soon becomes very rich, while most social groups of the population remain in poverty). Attempts to apply the methods of developing statistical physics in the study and research of phenomena in the financial-monetary and socio-economic systems is in the field of econophysics, already well known lately, but not yet valued at its fair value, and on the other hand criticized by opponents this direction rightly, because it cannot be an instrument and a philosophy for all financial-monetary and socio-economic phenomena. The analysis of the chaos model in the dynamics of the interaction of economic agents is a relatively advanced approach in which the rules for choosing the means and conditions of transfer are not random, because they are caused by nonlinear processes that occur in a chaotic way. Moving away from the deterministic modeling of all possible reasons for the exchange of sums of money between agents with a certain characteristic, at certain special moments of time, in the opinion of researchers it is considered possible to express unpredictability by random noise. This abstraction greatly simplifies the model, having the only exchange rule consisting of three stages: 1 ) random selection of agents $i$ and $j$ (buyer and seller); 2) random choice of price in the range [0, mi], where $\mathrm{mi}$ is the amount of money from buyer $\mathrm{i} ; 3$ ) the transfer of money from agent $\mathrm{i}$ to agent $\mathrm{j}$ and, therefore, the reciprocal change of cash balances $m$ for agents takes place decrease in $i$ and increase in $\mathrm{j}$. Respectively, the mathematical problem of distribution (division) of limited resources between a large number of agents can be represented in the form of a monetary balance, which as a result of an iteration of the exchange will have the following form: $m_{i} \rightarrow \underline{m_{i}}=\underline{m_{i}}-\Delta \mathrm{m} ; m_{j} \rightarrow m_{j}=m_{j}+$ $\Delta \mathrm{m}$.

In the conclusion of this paper, the author comes with theoretical conclusions from the mathematical model. The main conclusion of this model is that the loan interest rate mechanism generates an even greater entropy of the system and contradicts the logic of economic relations based on the equivalent exchange of goods. In the presence of loan interest in the economy, the rate of increase in prices for consumer goods will always exceed the rate of increase of the income of the population involved in production. Such a complex problem will cause a permanent lack of means of payment which, when certain thresholds are reached, will lead to systemic crises. The lending rate creates a chronic shortage of money in circulation, helps to destroy solvent demand and reduce the economic activity of the population and entrepreneurs. In the absence of a nominal limit 
on the maximum amount of debt and stabilization mechanisms for the distribution of money in the system, the phenomenon of bankruptcy is the mechanism by which debt stabilization is ensured and bringing the system to a new state with relatively low entropy. The author considers that bankruptcy is the only tool that allows us to "reset" the balance when the debt increases. Therefore, bankruptcy "cancels" the debt from the bank's balance sheet.

The modernization of economic systems by implementing complex projects and measures to ensure increasing order and the degree of interaction of their elements, means an increase in entropy.

In the literature, the prevailing opinion is the dissatisfaction of traditional systems of enterprise performance indicators, methods of accounting for costs and results, involving linear and nonlinear extrapolations of their changes in production volumes. This is due to the development of an understanding of alternatives to managerial decision making based on estimates based on nontraditional cost differentiation, which allow additional profits to be seen in situations where orders are placed at a cost below cost. In this regard, new approaches are being developed on a large scale, which take into account the random choice of economic processes.

The economy of entropy considers the enterprise as an open nonlinear dynamic system, where in the process of self-organization a new order and structures are formed through chaos. The company operates in a non-statistical market uncertainty. Any projects or complex measures at the enterprise that even have initial conditions close to each other, and in the future have significant differences in the evaluation of the result.

\section{REFERENCES}

Anghel, S., \& Stănescu, C. (2016). Termodinamică și fizica moleculară. Editura Universităţii din Pitești.

Bran, P. (2003). Finanțele întreprinderii. Ed. Economică, Bucharest.

Bran, P. (2004). Economica valorii. Editura ASE, Bucharest.

Fatemi, A., M., \& Fooladi, I., J. (2013). Sustainable finance: A new paradigm. Global Finance Journal, 24 (2), 101-113.

Georgescu-Roegen, N., (1971). Legea entropiei și procesul economic/ The Entropy Law and the Economic Process. Harvard University Press.

Melinikov, V., A. (2011). Мельников, B.A., Квантовая Экономика Действий, Издательство: СФУ г. Красноярск, ISBN: 978-5-7638-2280-9

Podolinsky, S.A. (1991). Human Labor and Its Relation to the Distribution of Energy (Podolinsky 1880).

Romanian Government. (2018). Romania's Sustainable Development Strategy 2030. Romania.

Ryszawska, B. (2018). Sustainable Finance: Paradigm Shift. Finance and Sustainability, pp. 219231, Part of the Springer Proceedings in Business and Economics book series. https://doi.org/10.1007/978-3-319-92228-7 19

Schoenmaker, D. \& Schramade, W. (2019). Principles of Sustainable Finance. Oxford University Press, 2019, Available at SSRN:https://ssrn.com/abstract=3282699

Slovohotov, Yu.L. (2012). Physics vs. Sociophysics. Part 1. Physical Grounds of Social Phenomena. Processes in Society and Solar Forcing. Mechanical Movement in a System of Living Particles.

Stoletov, A. (2003). СТОЛЕТОВ Александр Александрович, Формирование информационного обеспечения устойчивого развития промышленного предприятиятема диссертации по экономике, полный текст автореферата, Белгород-2003

United Nations (2015). Transforming our world: the 2030 Agenda for Sustainable Development.

World Bank Group (2017). Roadmap for a Sustainable Financial System, A Un Environment World Bank Group Initiative. United States. 
Yongfan, X. (2012). The Study on University Financial Management under Knowledge Economy. Physics Procedia, Volume 33, Pages 1913-1919.

Zhou, R., Cai, R., \& Tong, G. (2013). Applications of Entropy in Finance: A Review. Entropy, 15(11), 4909-4931; https://doi.org/10.3390/e15114909

Ziolo, M., Filipiak, B.Z., Bak, I., \& Katarzyna Cheba, K. (2019). How to Design More Sustainable Financial Systems: The Roles of Environmental, Social, and Governance Factors in the Decision-Making Process. Sustainability, 11(20), 5604; https://doi.org/10.3390/su11205604 